\title{
Stator Flux Observer for Induction Motor Based on Tracking Differentiator
}

\author{
Dafang Wang, ${ }^{1}$ Zhenfei Hu, ${ }^{1}$ Cheng Zhu, ${ }^{2}$ Chuanwei Zhou, ${ }^{1}$ and Yajing Xie ${ }^{1}$ \\ ${ }^{1}$ School of Automotive Engineering, Harbin Institute of Technology, Weihai 264209, China \\ ${ }^{2}$ China Automotive Technology \& Research Center, Tianjin 300300, China \\ Correspondence should be addressed to Dafang Wang; wdflcjl@163.com
}

Received 23 September 2013; Revised 21 October 2013; Accepted 4 November 2013

Academic Editor: Rongni Yang

Copyright (c) 2013 Dafang Wang et al. This is an open access article distributed under the Creative Commons Attribution License, which permits unrestricted use, distribution, and reproduction in any medium, provided the original work is properly cited.

\begin{abstract}
Voltage model is commonly used in direct torque control (DTC) for flux observing of asynchronous motor. In order to improve low-speed and dynamic performance of the voltage model, a modified low-pass filter (LPF) algorithm is proposed. Firstly, the tracking differentiator is brought in to modulate the measured stator current, which suppresses the measurement noise, and then amplitude and phase compensation is made towards the stator electromotive force (EMF), after which the stator flux is obtained through a low-pass filter. This method can eliminate the dynamic error of flux filtered by LPF and improve low-speed performance. Experimental results demonstrate effectiveness and improved dynamic performance of such method.
\end{abstract}

\section{Introduction}

The direct torque control technology based on stator flux orientation has been widely used in high-performance induction motor control system. It has the advantages of simple structure, not being sensitive to motor parameters, and so forth $[1,2]$. The key of achieving direct torque control of asynchronous motor effectively lies in the accurate obtaining of stator flux information; especially observing motor flux exactly at a low stator frequency is even a big issue of AC speed regulation [3-5].

In the aspect of robust estimator, scholars have done a lot of research work. Reference [6] considers the modeling and adaptive output tracking of an FCTFPM as a nonlinear system with unknown nonlinearities by utilizing HGO and RBF neural networks. A fuzzy reliable control strategy has been presented for the tracking problem of the longitudinal dynamics of FAHVs model with actuator or sensor faults and external disturbance. Based on the T-S fuzzy modeling technology, a T-S fuzzy model has been constructed to represent the nonlinear dynamics of the FAHVs [7]. Reference [8] presents a fault tolerant tracking controller for a VTOL aircraft flight in uncertain conditions. The considered system contains structured uncertainties which affect the mechanical parameters of the air vehicle. Reference [9] investigates the energy-to-peak filtering problem for nonuniformly sampled nonlinear systems. The sampled nonlinear systems are modeled by T-S fuzzy systems under the discretetime framework. Reference [10] is devoted to the ammonia coverage ratio estimation problem in SCR systems. Reference [11] studies the state estimation problem for discrete-time systems subject to network-induced delay. By considering the occurrence probability for the delay, the exponential meansquare stability and the $H_{\infty}$ performance are exploited for the estimation error system. Reference [12] investigates the $H_{\infty}$ filtering problem for T-S fuzzy systems under the discretetime framework. By using Finsler's lemma, a new $H_{\infty}$ criterion for discrete-time fuzzy systems is obtained. With the partition technique, the Lyapunov weighting matrices and the parameters to be designed are decoupled.

Voltage model is the basic method of the following stator flux. It uses an ideal integrator described in formula (1). The algorithm of this model is simple which only need to know the stator resistance, which is why the flux observing method which is based on voltage model has always been given special importance [13, 14]. Consider

$$
\psi_{s}=\int\left(\mathbf{u}_{s}-\mathbf{i}_{s} R_{s}\right) d t
$$


Although the voltage model is quite simple, there are still some problems in practical application [15]. (1) A small DC bias or drift in the current measurement channel will cause the integrator saturation. (2) The stator resistance variation in low stator frequency makes the stator flux amplitude and phase observations have a big error. (3) The initial value of the integral produces the dc bias in the observed flux amplitude.

In order to eliminate the effect of DC bias, it is proposed in [16] that the pure integrator should be replaced with low-pass filter, but amplitude and phase error of flux can be introduced to it. Adopting a programmable cascaded low-pass filter can overcome the effect of zero drift theoretically [17], but the cutoff frequency is of high precision. It is difficult to get the desired effect in practical application, and the dynamic performance is poor. Using improved PLL to observe the stator flux is proposed in [18], but this method needs to use the motor speed information based on permanent magnet synchronous motor, and the system has two convergence points meanwhile.

The biggest reason why flux observation is inaccurate is that the DC bias and unbalanced gain exist in current measurement channel; hence this paper reduces the current measurement interference by using tracking differentiator $[19,20]$ to filter the measuring stator current; it also restrains the DC component of stator current by using low-pass filter instead of pure integral, and it eliminates the amplitude attenuation and phase error brought by low-pass filter by using the back EMF compensation algorithm. Experimental results demonstrate effectiveness and improved dynamic performance of such method.

\section{Traditional Method of Stator Flux Estimation}

The voltage model for flux observation is obtained according to the stator voltage equation. Stator voltage equation and flux equation are expressed as

$$
\begin{gathered}
\mathbf{u}_{s}=R_{s} \mathbf{i}_{s}+\frac{d \psi_{s}}{d t}, \\
\psi_{s}=\int\left(\mathbf{u}_{s}-\mathbf{i}_{s} R_{s}\right) d t,
\end{gathered}
$$

where $\mathbf{u}_{s}$ is the stator voltage, $R_{s}$ is the stator resistant, $\mathbf{i}_{s}$ is the stator current, and $\psi_{s}$ is the stator flux.

Equation (3) is called the U-I model or the voltage model of flux estimator. Since the formula contains a pure integrator, small DC bias can cause integral saturation which will result in flux estimation error. So it is usual to replace pure integral with the first-order low-pass filter in voltage model; namely, let the integral input signal go through a high-pass filter firstly to filtrate the DC component.

The stator flux has invariant amplitude in a steady state revolving in the synchronous frequency, which can be expressed as

$$
\psi_{s}=\left|\psi_{s}\right| e^{j \omega_{e} t}=\left|\psi_{s}\right| \angle \omega_{e} t
$$

where $\omega_{e}$ is the synchronous frequency of the motor.
Equations (2) and (4) become

$$
\begin{gathered}
\frac{d \psi_{s}}{d t}=j \omega_{e} * \psi_{s}=\mathbf{u}_{s}-\mathbf{i}_{s} R_{s}, \\
\psi_{s}=\frac{\mathbf{u}_{s}-\mathbf{i}_{s} R_{s}}{j \omega_{e}} .
\end{gathered}
$$

Equation (5) is the expression of actual stator flux.

When observing stator flux through low-pass filter, the following equation can be written:

$$
\begin{gathered}
\frac{d \widehat{\psi}_{s}}{d t}+\omega_{c} \widehat{\psi}_{s}=j \omega_{e} * \widehat{\psi}_{s}+\omega_{c} \widehat{\psi}_{s}=\mathbf{u}_{s}-\mathbf{i}_{s} R_{s}, \\
\widehat{\psi}_{s}=\frac{\mathbf{u}_{s}-\mathbf{i}_{s} R_{s}}{j \omega_{e}+\omega_{c}},
\end{gathered}
$$

where $\widehat{\psi}_{s}$ is the stator flux which is observed by low-pass filter and $\omega_{c}$ is the cutoff frequency of the low-pass filter.

The connection between the estimated stator flux $\widehat{\psi}_{s}$ and the actual stator flux $\psi_{s}$ can be concluded from (5) and (6) which can be expressed as

$$
\begin{gathered}
\widehat{\psi}_{s}=\frac{\omega_{e}}{\sqrt{\omega_{e}^{2}+\omega_{c}^{2}}} \psi_{s} \angle \theta, \\
\theta=\frac{\pi}{2}-\arctan \frac{\omega_{e}}{\omega_{c}} .
\end{gathered}
$$

From (7), it is clear that errors of flux in the amplitude and the phase result from the replacement of pure integral with a low-pass filter. The higher the cutoff frequency is, the more serious the distortion is shown in the flux amplitude and phase.

According to the principle of the direct torque control, the flux error can affect the steady state and dynamic operation of asynchronous motor directly. Direct torque control selects the appropriate voltage vector according to the observed flux and torque. Meanwhile the low-pass filter cuts down the flux amplitude, so when the observing flux reached a given value, the actual flux has already been far beyond that, which leads to the saturation of motor magnetic field. Phase shift of the observed flux can influence the accurate selection of voltage vector as well as the control characteristic of the motor. Besides, the estimation of torque in direct torque control is also affected by flux value directly. Therefore it is essential to have amplitude and phase compensation for the result of lowpass filter. Traditional method of flux observing is shown in Figure 1 .

\section{Improved Method of Flux Observing}

3.1. Modified Low-Pass Filter (LPF) Compensation Algorithm. Make amplitude and phase compensation for the result of the low-pass filter as follows:

$$
\widehat{\psi}_{s} \mathbf{G}=\psi_{s},
$$

where $\widehat{\psi}_{s}$ is the stator flux which is observed by low-pass filter, $\mathrm{G}$ is the penalty function, and $\psi_{s}$ is the stator flux. 


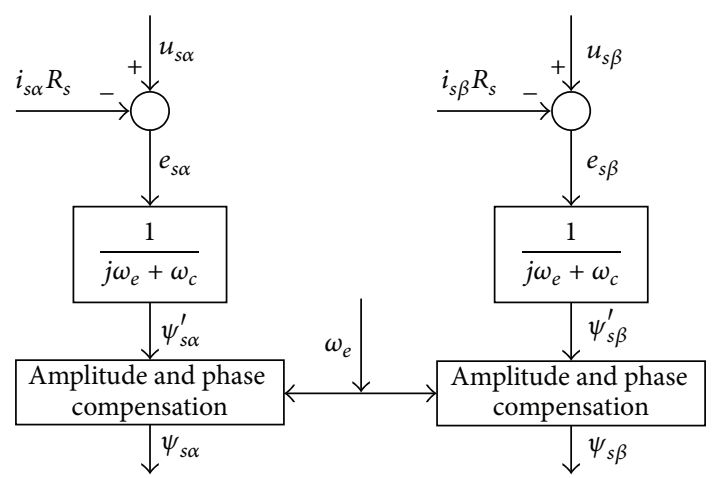

FIgURE 1: Traditional method of flux observing.

According to (7), the penalty function $\mathbf{G}$ can be expressed as

$$
\begin{gathered}
\mathbf{G}=\frac{\sqrt{\omega_{e}^{2}+\omega_{c}^{2}}}{\omega_{e}} e^{j\left(\arctan \left(\omega_{e} / \omega_{c}-\pi / 2\right)\right)}=\frac{\sqrt{\omega_{e}^{2}+\omega_{c}^{2}}}{\omega_{e}} e^{j \rho\left(\omega_{e}\right)}, \\
e^{j \rho\left(\omega_{e}\right)}=\cos \left[\rho\left(\omega_{e}\right)\right]+j \sin \left[\rho\left(\omega_{e}\right)\right] \\
\cos \left[\rho\left(\omega_{e}\right)\right]=\frac{\omega_{e}}{\sqrt{\omega_{e}^{2}+\omega_{c}^{2}}}, \\
\sin \left[\rho\left(\omega_{e}\right)\right]=\frac{\omega_{c}}{\sqrt{\omega_{e}^{2}+\omega_{c}^{2}}}
\end{gathered}
$$

where $\omega_{e}$ is the synchronous frequency of the motor $\omega_{c}$ is the cutoff frequency of the low-pass filter.

By choosing appropriate cutoff frequency, this compensation algorithm can make the flux observer have a better ability in restraining DC drift and also have a strong ability of anti-interference. But this algorithm has a poor dynamic performance. The estimation of flux value will have big error when stator current frequency has a sudden change [21]. For this reason the sequence of applying the low-pass filtering algorithm and the flux compensation can be exchanged, making compensation for the back electromotive force firstly as follows:

$$
\mathbf{E}_{s}=\mathbf{u}_{s}-\mathbf{i}_{s} R_{s}, \quad \widehat{\mathbf{E}}_{s} \mathbf{G}=\mathbf{E}_{s} .
$$

In the $\alpha-\beta$ coordinate system, back electromotive force components $e_{s \alpha}$ and $e_{s \beta}$ are at $\pi / 2$ space angle. Assuming that the stator flux is in counterclockwise rotation, it passes $\alpha$ axis firstly and then $\beta$ axis. Therefore in a constant flux control mode, $e_{s \alpha}$ and $e_{s \beta}$ have the same amplitude and different phase, which can be rewritten as

$$
e_{s \alpha}=j e_{s \beta}, \quad e_{s \beta}=-j e_{s \alpha}
$$

Combining (9) (11) leads to the following expression:

$$
\begin{aligned}
& e_{s \alpha}=\widehat{e}_{s \alpha}+\frac{\omega_{c}}{\omega_{e}} \widehat{e}_{s \beta}, \\
& e_{s \beta}=\widehat{e}_{s \beta}-\frac{\omega_{c}}{\omega_{e}} \widehat{e}_{s \alpha} .
\end{aligned}
$$

Practice shows that the optimal cutoff frequency for lowpass filter should be $20 \% \sim 30 \%$ of the synchronous frequency $\omega_{e}$ [16]. It is hard to estimate synchronous frequency of the motor when it is running, whereas the stator current frequency can be obtained through the detected current signal, so it can replace the synchronous frequency. Therefore the cutoff frequency of low-pass filter can be calculated as follows:

$$
\omega_{c}=\omega_{0}+k \omega_{i} \text {, }
$$

where $\omega_{0}$ is the initial value. It ensures that when rotating speed is close to zero, the cutoff frequency will not be too low. $\omega_{i}$ is the stator current frequency and $k$ is coefficient of proportionality (0.2-0.3).

According to the above, in order to achieve this modified low-pass filter algorithm, it is necessary to settle on the stator current frequency $\omega_{i}$. The space situation of the stator current in the $\alpha$ - $\beta$ coordinate system can be expressed as

$$
\theta_{i}=\arctan \left(\frac{i_{s \beta}}{i_{s \alpha}}\right),
$$

where the stator current frequency can be obtained by differentiating $\theta_{i}$; the discretization formula is shown as follows:

$$
\omega_{i(k)}=\frac{\theta_{(k)}-\theta_{(k-1)}}{\Delta T} .
$$

3.2. Tracking Differentiator. Because of the measurement noise, the stator current can affect the precision of flux observation; therefore, stator current needs to be filtered. Tracking differentiator (TD) is the essential part of ADRC [22]. The initial purpose of TD is to rationally extract continuous signal and differential signal from discontinuous or band random noise signal when it comes to the practical engineering problems. After a further research on TD, discretization form of TD was proposed, making it easier for computer calculation and better in filtering.

TD discretization formula can be written as

$$
\begin{gathered}
x_{1}(k+1)=x_{1}(k)+h * x_{2}(k), \\
x_{2}(k+1) \\
=x_{2}(k)+h * f s t\left(x_{1}(k)-v(k), x_{2}(k), r, h_{1}\right),
\end{gathered}
$$




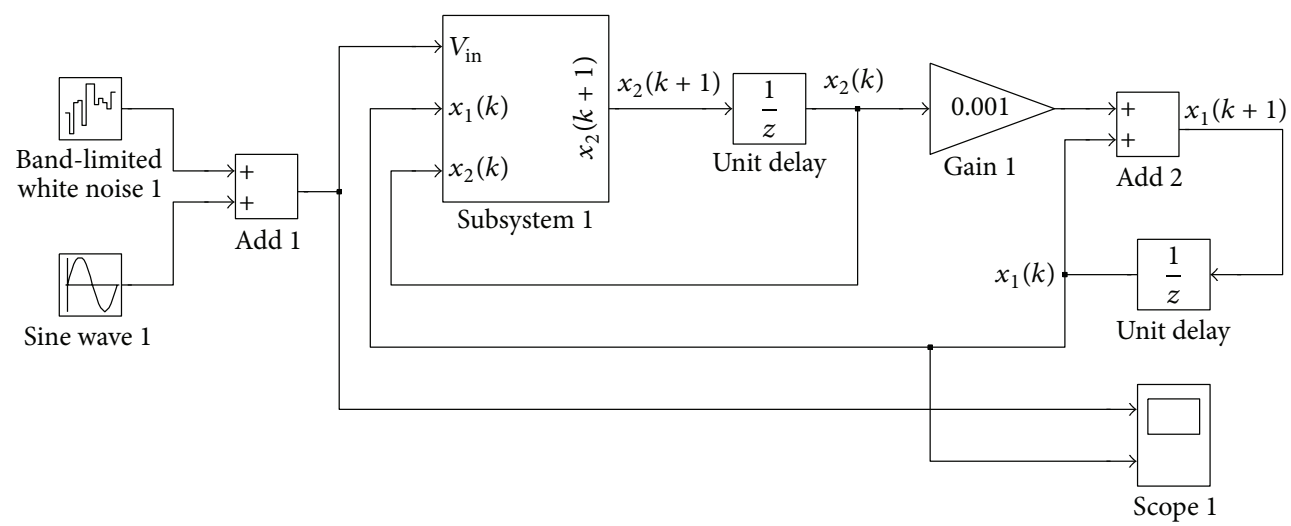

FIGURE 2: TD modeling in Simulink.

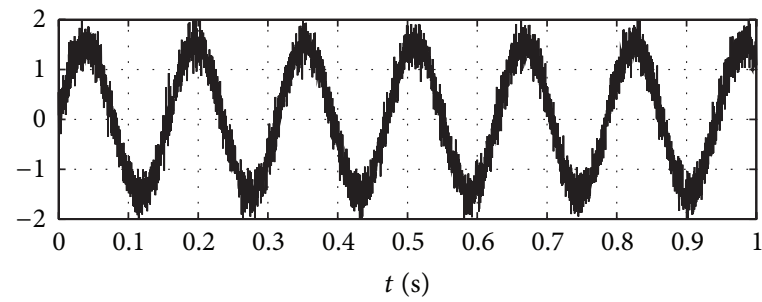

(a) Signal before filtering

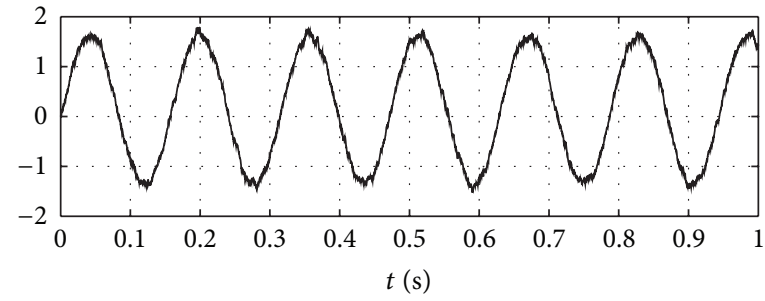

(b) Signal after filtering

FIGURE 3: Filtering result of TD.

where $v(k)$ is input signal, $x_{1}$ is the tracking signal of $v(k)$, and $x_{2}$ is the derivative of $x_{1}$ which can be seen as the derivative of input signal. Consider

$$
\begin{aligned}
& f s t\left(x_{1}(k)-v(k), x_{2}(k), r, h_{1}\right)=-r * \operatorname{sat}(g(k), \delta) \text {, } \\
& \delta=h_{1} * r, \quad \delta_{1}=h_{1} * \delta, \\
& e(k)=x_{1}(k)-v(k) \text {, } \\
& y(k)=e(k)+h_{1} * x_{2}(k), \\
& g(k)= \begin{cases}x_{2}(k)+\operatorname{sign}(y(k)) & \\
* \frac{\sqrt{8 r|y(k)|+\delta^{2}}-\delta}{2} & |y(k)| \geq \delta_{1} \\
x_{2}(k)+\frac{y(k)}{h_{1}} & |y(k)| \leq \delta_{1},\end{cases} \\
& \operatorname{sat}(x, \delta)= \begin{cases}\operatorname{sign}(x) & |x| \geq \delta \\
\frac{x}{\delta} & |x| \leq \delta,\end{cases}
\end{aligned}
$$

where $h$ is integration step and $r$ is a parameter that determines the tracking speed.

In order to validate the filtering performance of tracking differentiator, as shown in Figure 2, a Simulink simulation model is built with an interference input signal as follows:

$$
v(t)=\sin t+d(t)
$$

where $d(t)$ is the uniformly distributed random disturbance signal with the amplitude $1 \%$ and is used to simulate the measurement noise of the current sampling.

The simulation results are shown in Figure 3; it can be seen that the tracking differentiator restores the contaminated original signal. Hence this paper tries to introduce tracking differentiator to filter the stator current.

3.3. Build Up Complete Flux Observing Model. Based on the above analysis, the complete illustrative diagram of stator flux observing model is shown in Figure 4. The current which is used to count the back electromotive force is filtered by tracking differentiator and then compensate the back electromotive force, and then get the stator flux through the low-pass filter. Use the stator flux signal to calculate angular frequency and cutoff frequency which is fed back to compensation algorithm and low-pass algorithm.

\section{Experimental Verification}

4.1. Experimental Platform. In order to verify the performance of the flux observing model in this paper, an experimental platform is established for the asynchronous motor direct torque control system, as shown in Figure 5. The experimental platform is powered by programmable DC supply; the development suite is the high-voltage motor control and PFC Development Suite v2.0 from TI Company; the MCU is TMS320F28335; parameter of the triphase asynchronous motor is shown in Table 1 . The proposed method involves 


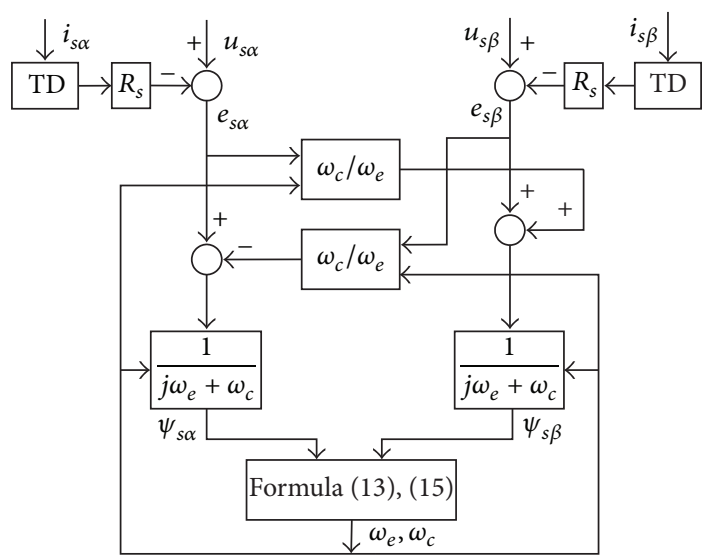

FIgURE 4: Model of the proposed stator flux observer.

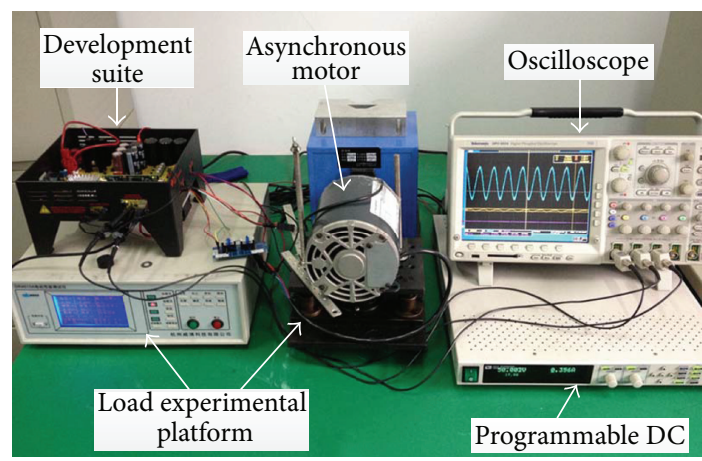

FIGURE 5: The experimental platform.

TABLE 1: Motor parameters.

\begin{tabular}{lc}
\hline Rated value & Parameter value \\
\hline Rated speed $1725 \mathrm{r} / \mathrm{min}$ & Stator resistance $11.05 \Omega$ \\
Rated power $184 \mathrm{~W}$ & Rotor resistance $6.11 \Omega$ \\
Rated voltage $220 \mathrm{~V}$ & Self-inductance $0.316423 \mathrm{H}$ \\
Rated torque $1 \mathrm{~N} \cdot \mathrm{m}$ & Mutual inductance $0.293939 \mathrm{H}$ \\
Rated current $1.3 \mathrm{~A}$ & Number of pole-pairs 2 \\
\hline
\end{tabular}

some division operations, requiring a higher speed processor. In this paper, we chose DSP28335, up to $150 \mathrm{MHz}$, which can meet the requirements.

In the control procedure of experiment, the control period is $100^{\mu s}$. The two flux observing methods are compared in the experiment; the result of the traditional method is shown in Figure 1, whereas the result of the method proposed in this paper is shown in Figure 4. Except the flux observing method, other conditions are all the same in this experiment.

4.2. Experimental Results. Figures 6 and 7 give the compared experimental waveforms of the two methods where the targeted motor speeds are both $150 \mathrm{r} / \mathrm{min}$. It can be seen from Figure 6 that when the targeted motor speed is higher, the speed waveforms are basically the same of the two methods. From Figure 7 it can be seen that the current waveforms are basically the same of the two methods as well, but current harmonic wave is smaller in the method proposed in this paper, which illustrates that the use of tracking differentiator in filtering has improved the current fluctuation.

With the targeted speed getting slower, the traditional method can barely guarantee performance of the motor control; Figures 8 and 9 give the compared experimental waveforms of the two methods where the targeted motor speeds are both $50 \mathrm{r} / \mathrm{min}$. It can be seen from Figure 8 that, in the traditional method, the motor speed has a huge fluctuation; that is to say, the DTC has already become invalid; the motor speed is kept around the targeted one and has a small fluctuation by using the flux observing method of this paper. From the current waveforms shown in Figure 9, it is clear that there are a lot of current harmonic waves and the waveform also has distortions in the traditional method, but current waveform in the method of this paper is still in good state.

When the targeted speed is set to be $25 \mathrm{r} / \mathrm{min}$, the experimental result of DTC system using traditional method has a poor performance, the motor operates intermittently, and the control is totally invalid, whereas the DTC system based on flux observing model of this paper can still run smoothly. Using the method of this paper, the speed and the current waveforms which are shown in Figure 10 aimed at a speed of $25 \mathrm{r} / \mathrm{min}$. The experimental results show that the flux observation method proposed in this paper can improve the low-speed performance of DTC.

Under the experimental condition that the speed changes sharply from $150 \mathrm{r} / \mathrm{min}$ to $50 \mathrm{r} / \mathrm{min}$ in the $4.5 \mathrm{~s}$, Figures 11 and 12 give the current waveforms of two methods. When the speed turns sharply, it is obvious that the load and current fluctuation are smaller in the method of this paper. When the targeted speed is $50 \mathrm{r} / \mathrm{min}$, under the experimental condition that the load torque changes sharply from $0 \mathrm{~N} \cdot \mathrm{m}$ to $0.3 \mathrm{~N} \cdot \mathrm{m}$ in the $4.5 \mathrm{~s}$, Figures 13, 14, and 15 show the speed and stator current and torque waveforms of two methods. When the load torque changes sharply, the torque of traditional method has a huge fluctuation, whereas in the method of this paper the torque has a small fluctuation. Experimental results demonstrate the improved dynamic performance of such flux observing method mentioned in this paper.

\section{Conclusion}

To solve the stator flux observation problem of asynchronous motor, the observation scheme that compensates for back EMF firstly and then filters through low-pass filter is proposed; at the mean time tracking differentiator is used to filter the stator current and the simple voltage model is retained, and all the above lead to the improvement of the dynamic precision of flux observing. This scheme can improve the dynamic and low-speed performance of the DTC system of induction motors. The accuracy of flux observation is less influenced by the stator frequency mutation, and there is less current harmonic waves with efficiently restrained torque fluctuation. 


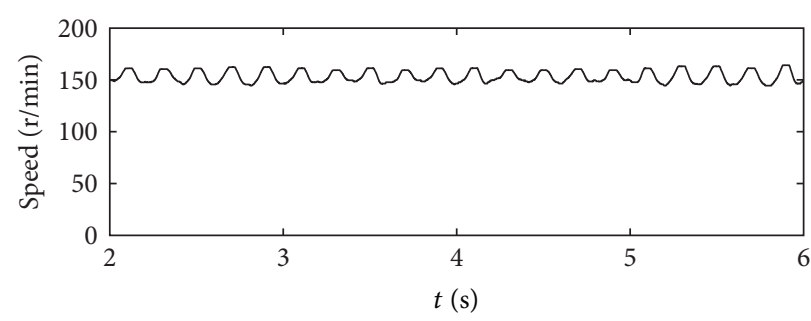

(a) Traditional method

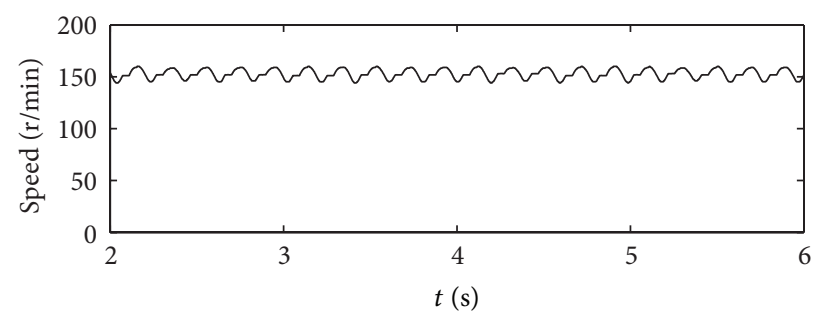

(b) Method in this paper

FIGURE 6: Motor speed waveform when target speed is $150 \mathrm{r} / \mathrm{min}$.

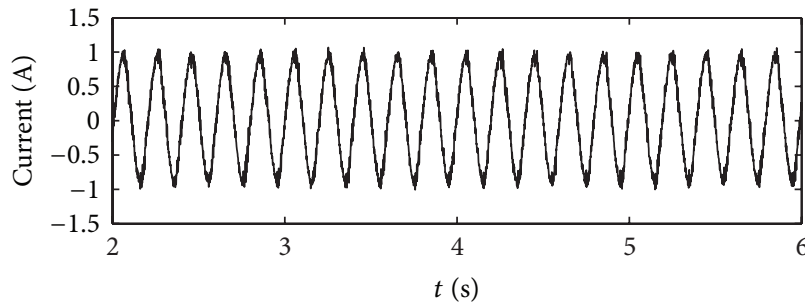

(a) Traditional method

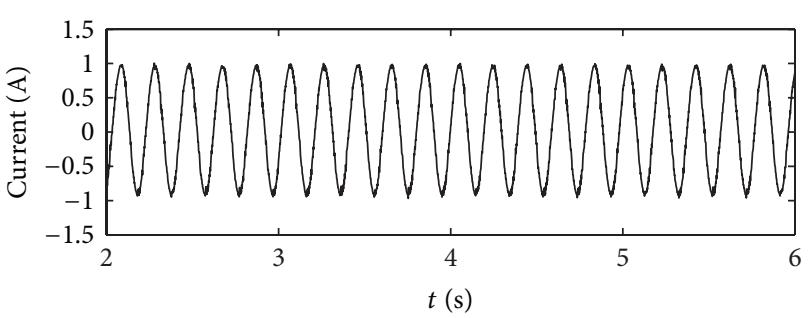

(b) Method in this paper

FIGURE 7: Stator current waveform when target speed is $150 \mathrm{r} / \mathrm{min}$.

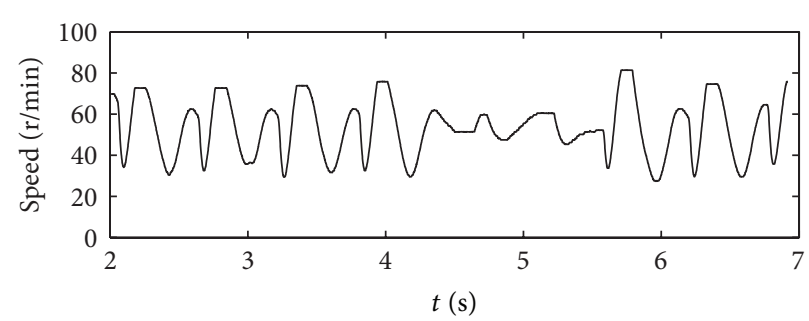

(a) Traditional method

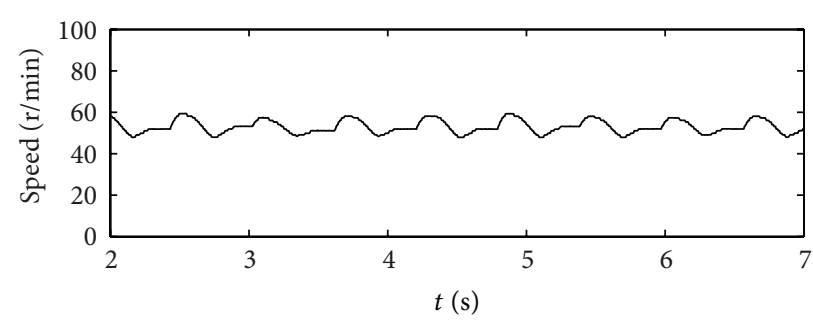

(b) Method in this paper

FIGURE 8: Motor speed waveform when target speed is $50 \mathrm{r} / \mathrm{min}$.

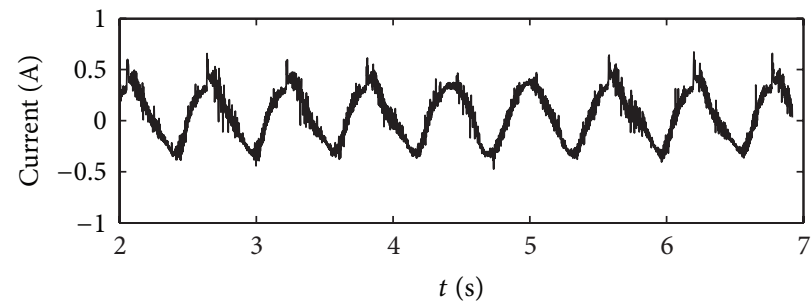

(a) Traditional method

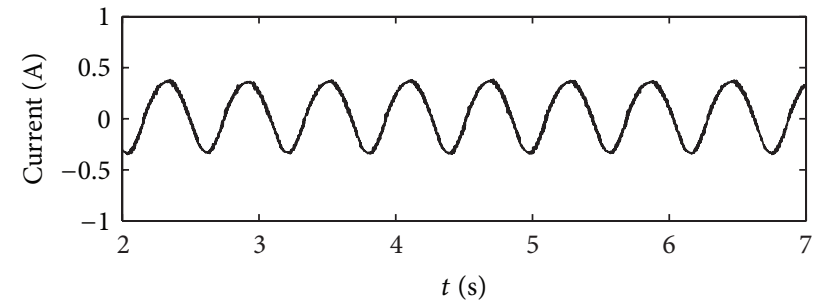

(b) Method in this paper

FIGURE 9: Stator current waveform when target speed is $50 \mathrm{r} / \mathrm{min}$.

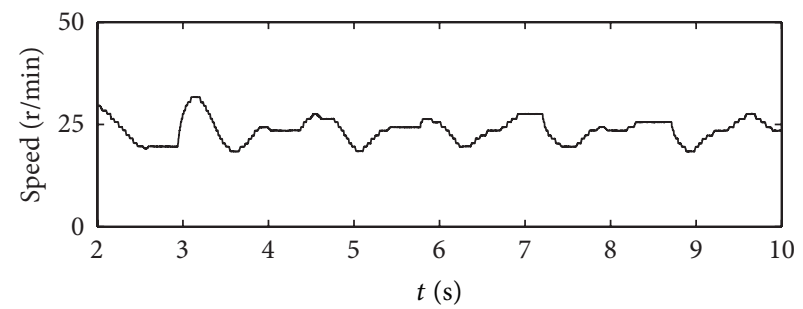

(a) Motor speed

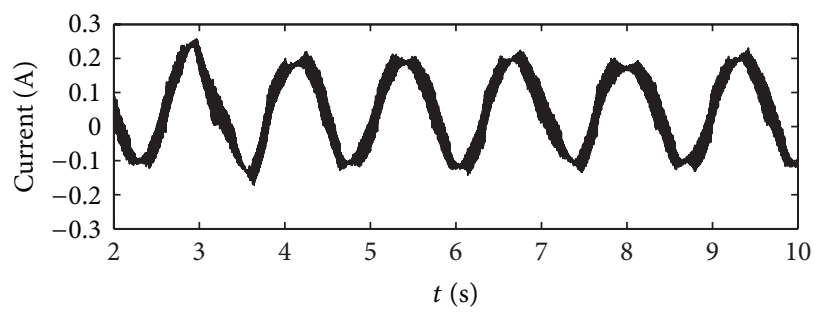

(b) Stator current

FIGURE 10: Waveforms with the proposed method when target speed is $25 \mathrm{r} / \mathrm{min}$. 


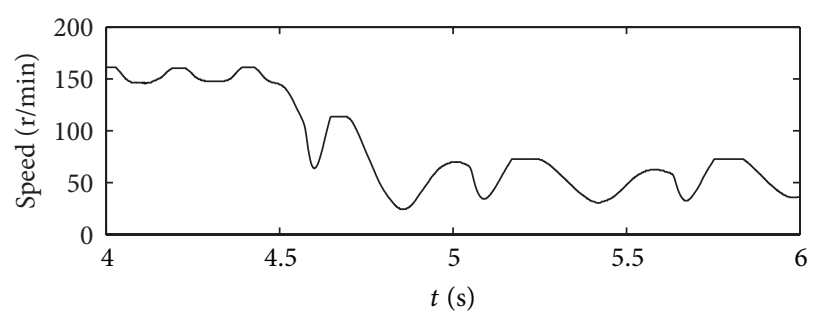

(a) Traditional method

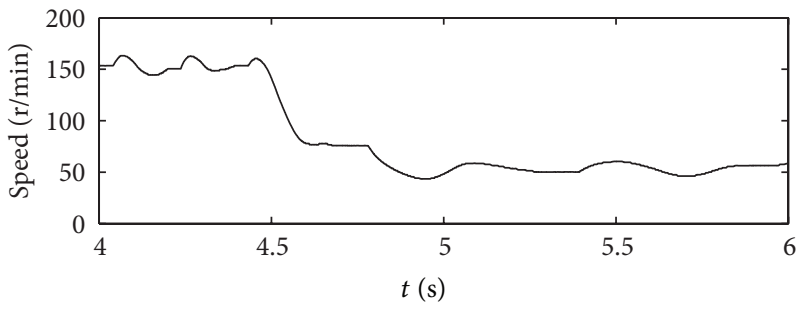

(b) Method in this paper

FIGURE 11: Motor speed waveform with speed step input from $150 \mathrm{r} / \mathrm{min}$ to $50 \mathrm{r} / \mathrm{min}$.

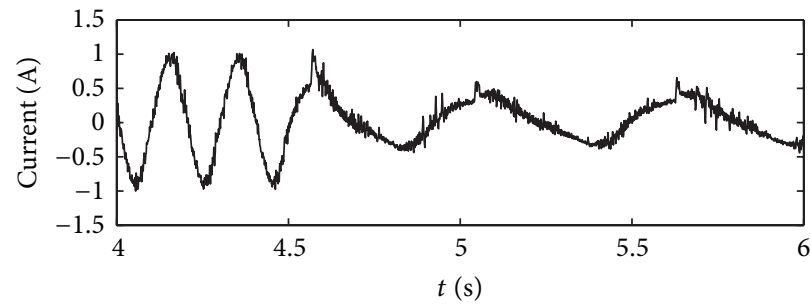

(a) Traditional method

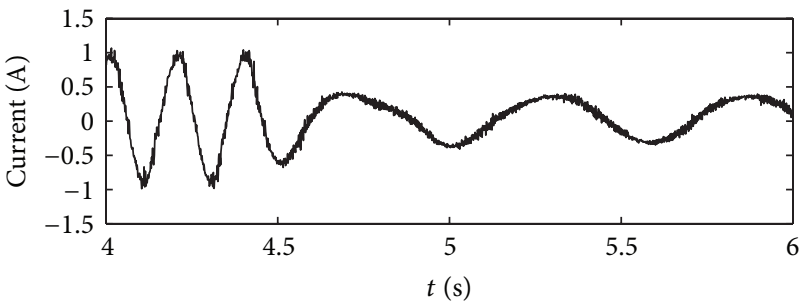

(b) Method in this paper

FIGURE 12: Stator current waveform with speed step input from $150 \mathrm{r} / \mathrm{min}$ to $50 \mathrm{r} / \mathrm{min}$.

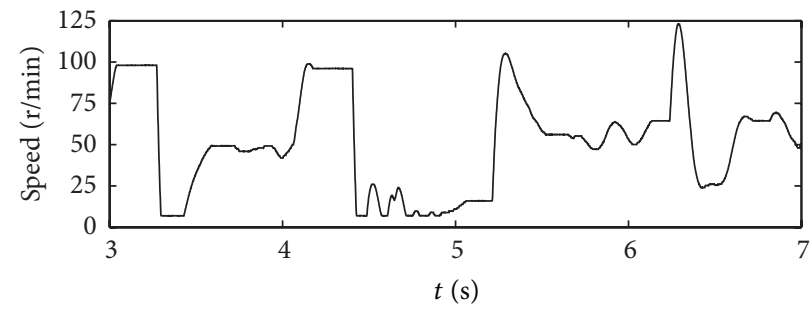

(a) Traditional method

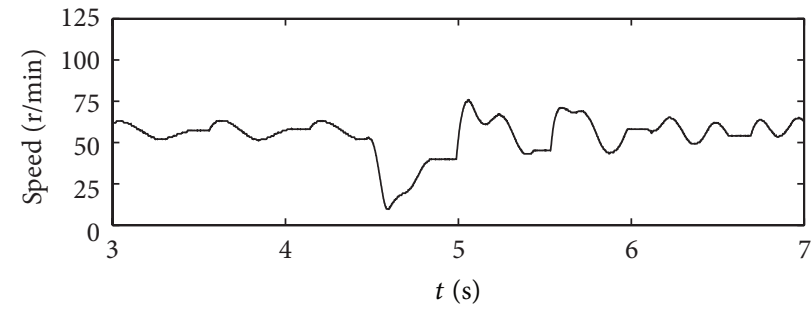

(b) Method in this paper

FIGURE 13: Motor speed waveform with torque input from $0 \mathrm{~N} \cdot \mathrm{m}$ to $0.3 \mathrm{~N} \cdot \mathrm{m}$.

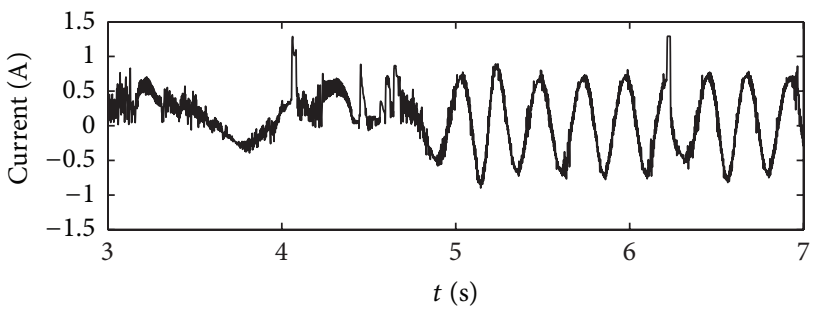

(a) Traditional method

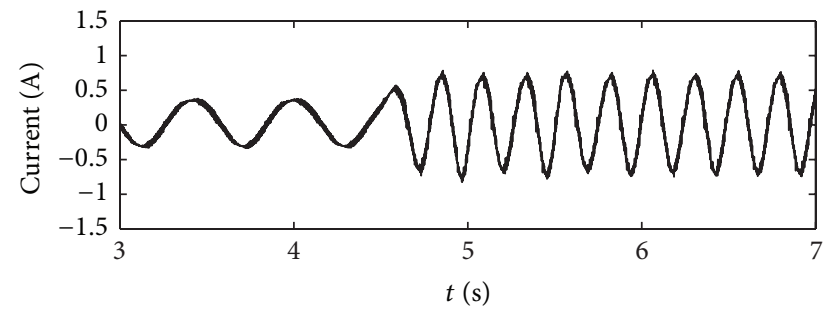

(b) Method in this paper

Figure 14: Stator current waveform with torque input from $0 \mathrm{~N} \cdot \mathrm{m}$ to $0.3 \mathrm{~N} \cdot \mathrm{m}$.

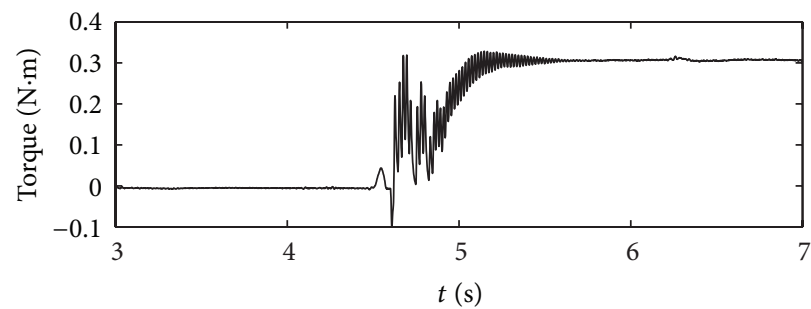

(a) Traditional method

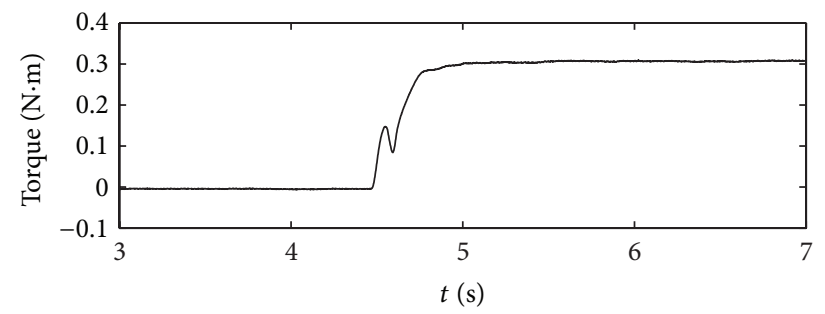

(b) Method in this paper

FIgURE 15: Torque waveform with torque input from $0 \mathrm{~N} \cdot \mathrm{m}$ to $0.3 \mathrm{~N} \cdot \mathrm{m}$. 


\section{Conflict of Interests}

The authors declare that there is no conflict of interests regarding the publication of this paper.

\section{Acknowledgments}

The work is sponsored by the Aerospace Support Technology Fund (2013-HT-HGD09), the National Laboratory for Electric Vehicles Foundations (NELEV-2013-004), Shandong Province Outstanding Young Scientists Research Award Funds (BS2012NJ001), and Beijing Science and Technology Project (Z121100005612001).

\section{References}

[1] Q.-M. Cheng, Y.-M. Cheng, Y.-F. Wang, and M.-M. Wang, "Overview of control strategies for AC motor," Power System Protection and Control, vol. 39, no. 9, pp. 145-154, 2011.

[2] W. Liu, H. Shen, L.-G. Gao, and H.-Z. Rong, "Study on direct torque control of brushless doubly-fed machines used for wind power generation," Power System Protection and Control, vol. 38, no. 5, pp. 77-81, 2010.

[3] Q. Wu and C. Shao, "Application of tracking-differentiator on stator flux estimation for induction motor," Chinese Journal of Mechanical Engineering, vol. 44, no. 12, pp. 291-295, 2008.

[4] C. Zhenfeng, Z. Yanru, L. Jie et al., "Speed identification for induction motor based on improved flux observer," Transactions of China Electrotechnical Society, vol. 27, no. 4, pp. 42-47, 2012.

[5] L.-Z. Wang, "Simulation of improved direct torque control system for permanent magnet synchronous motor," Power System Protection and Control, vol. 37, no. 19, pp. 65-68, 2009.

[6] H. R. Karimi and A. Babazadeh, "Modeling and output tracking of transverse flux permanent magnet machines using high gain observer and RBF Neural network," ISA Transactions, vol. 44, no. 4, pp. 445-456, 2005.

[7] X. Hu, H. Gao, H. R. Karimi, L. Wu, and C. Hu, "Fuzzy reliable tracking control for flexible air-breathing hypersonic vehicles," International Journal of Fuzzy Systems, vol. 13, no. 4, pp. 323334, 2011.

[8] M. Chadli, S. Aouaouda, H. R. Karimi et al., "Robust fault tolerant tracking controller design for a VTOL aircraft," Journal of the Franklin Institute, vol. 350, no. 9, pp. 2627-2645, 2013.

[9] H. Zhang, Y. Shi, and J. Wang, "On energy-to-peak filtering for nonuniformly sampled nonlinear systems: a Markovian jump system approach," IEEE Transactions on Fuzzy Systems, 2013.

[10] H. Zhang, J. Wang, and Y. Y. Wang, "Robust filtering for ammonia coverage estimation in Diesel engine selective catalytic reduction (SCR) systems," ASME Transactions, Journal of Dynamic Systems, Measurement, and Control, vol. 135, no. 6, Article ID 064504, 7 pages, 2013.

[11] H. Zhang, Y. Shi, and M. X. Liu, " $H_{\infty}$ switched filtering for networked systems based on delay occurrence probabilities," ASME Transactions, Journal of Dynamic Systems, Measurement, and Control, vol. 135, no. 6, Article ID 061002, 5 pages, 2013.

[12] H. Zhang, Y. Shi, and A. Saadat Mehr, "On $H_{\infty}$ filtering for discrete-time takagi-sugeno fuzzy systems," IEEE Transactions on Fuzzy Systems, vol. 20, no. 2, pp. 396-401, 2012.

[13] Z.-M. He, Y. Liao, and D.-W. Xiang, "Improvement of lowpass filter algorithm for stator flux estimator," Proceedings of the Chinese Society of Electrical Engineering, vol. 28, no. 18, pp. 61-65, 2008.

[14] Y. Zhang, J. Wang, and H. Li, "A method of the stator flux EXF estimation for induction motors based on genetic algorithm optimizing," Transactions of China Electrotechnical Society, vol. 24, no. 9, pp. 64-70, 2009.

[15] E. Zhou, X. Fu, X. Wu, and P. Dai, "Flux observer for elimination of current measurement error at low stator frequency," Transactions of China Electrotechnical Society, vol. 26, no. 6, pp. 67-72, 2011.

[16] Z. Xu and Q. Wenlong, "A novel compensation of stator flux estimating in low speed," Advanced Technology of Electrical Engineering and Energy, vol. 22, no. 3, pp. 50-54, 2003.

[17] T.-W. Chun, M.-K. Choi, and B. K. Bose, "A novel start-up scheme of stator flux oriented vector controlled induction motor drive without torque jerk," in Proceedings of the 36th IAS Annual Meeting Conference Record of the Industry Applications (IAC '01), pp. 148-153, Chicago, Ill, USA, October 2001.

[18] J.-W. Gao, X.-H. Wen, J.-W. Chen, and F. Zhao, "Novel motor stator flux observer based on PLL," Proceedings of the Chinese Society of Electrical Engineering, vol. 27, no. 18, pp. 41-47, 2007.

[19] J. Q. Han and L. L. Yuan, "The discrete form of a trackingdifferentiator," Journal of Systems Science and Mathematical Sciences, vol. 19, no. 3, pp. 268-273, 1999.

[20] L.-Q. Wu, H. Lin, and J.-Q. Han, "Study of tracking differentiator on filtering," Journal of System Simulation, vol. 16, no. 4, pp. 651-652, 2004.

[21] L. Gang, L. Du, R. Yifeng et al., "Improvement research of induction motor stator flux observation method," Electric Drive, vol. 40, no. 8, pp. 28-30, 2010.

[22] L. Hongbo, Z. Kai, Z. Hui et al., "An improved close-loop rotor flux observer and speed estimation of induction motor based on active disturbance rejection," Transactions of China Electrotechnical Society, vol. 27, no. 4, pp. 59-64, 2012. 


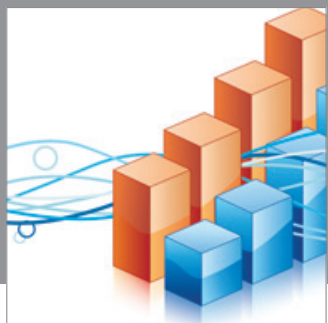

Advances in

Operations Research

mansans

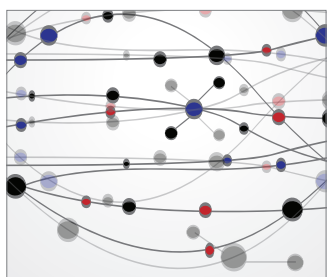

The Scientific World Journal
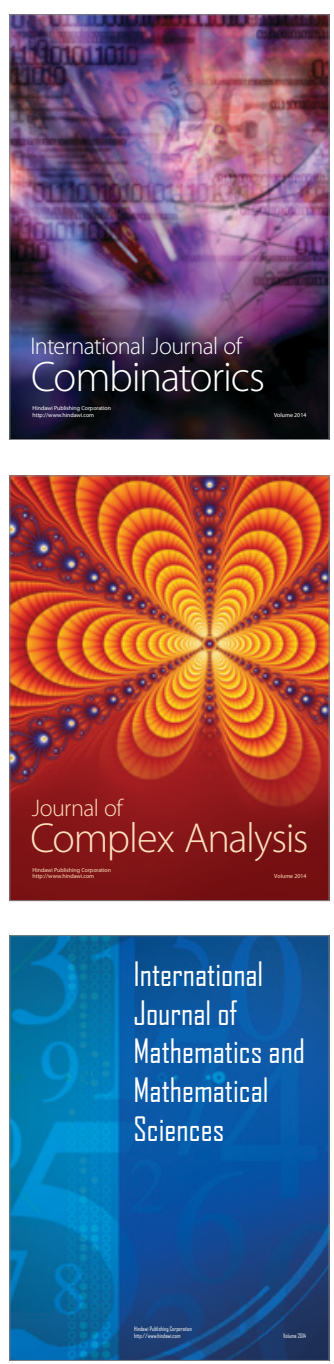
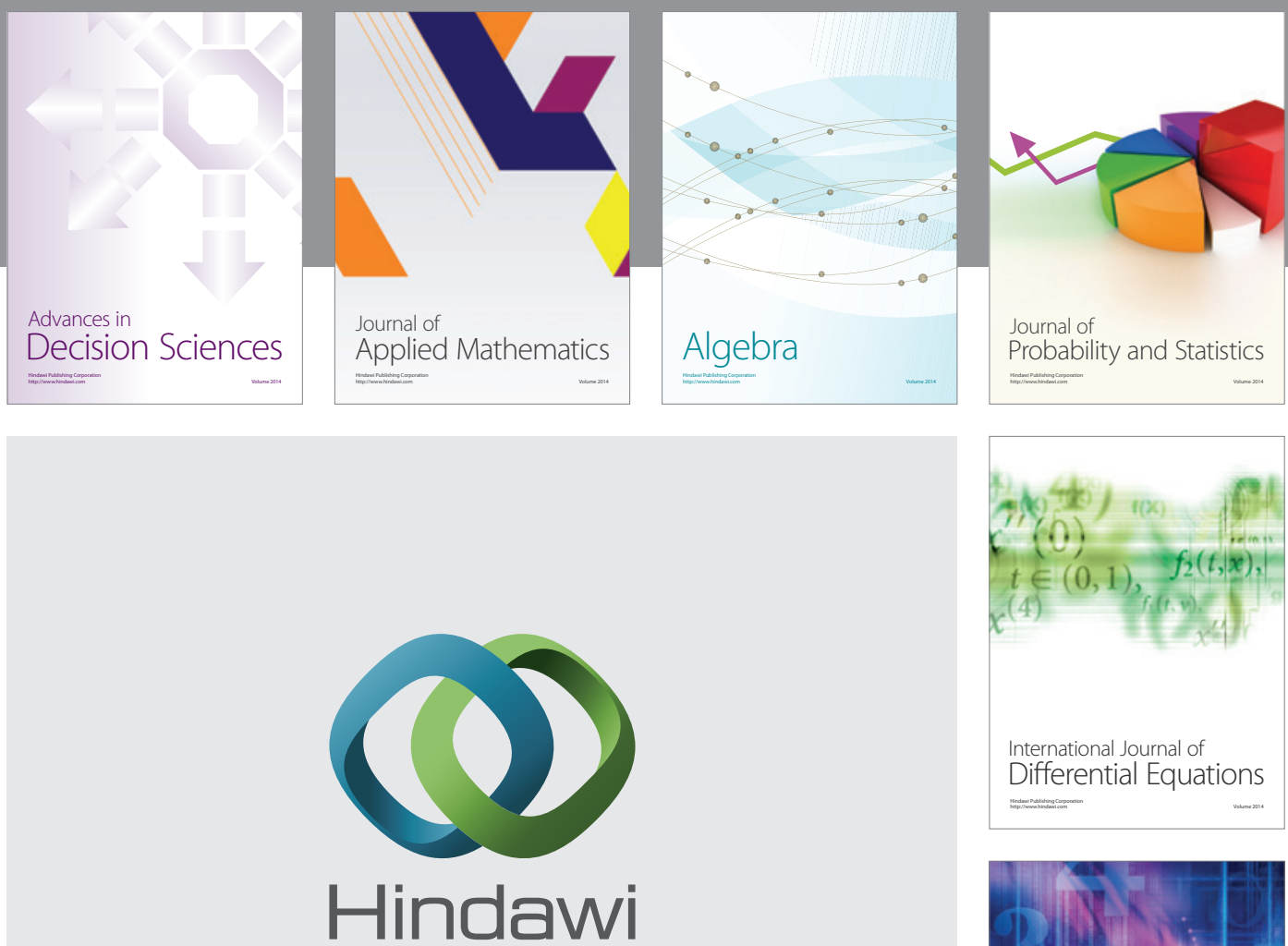

Submit your manuscripts at http://www.hindawi.com
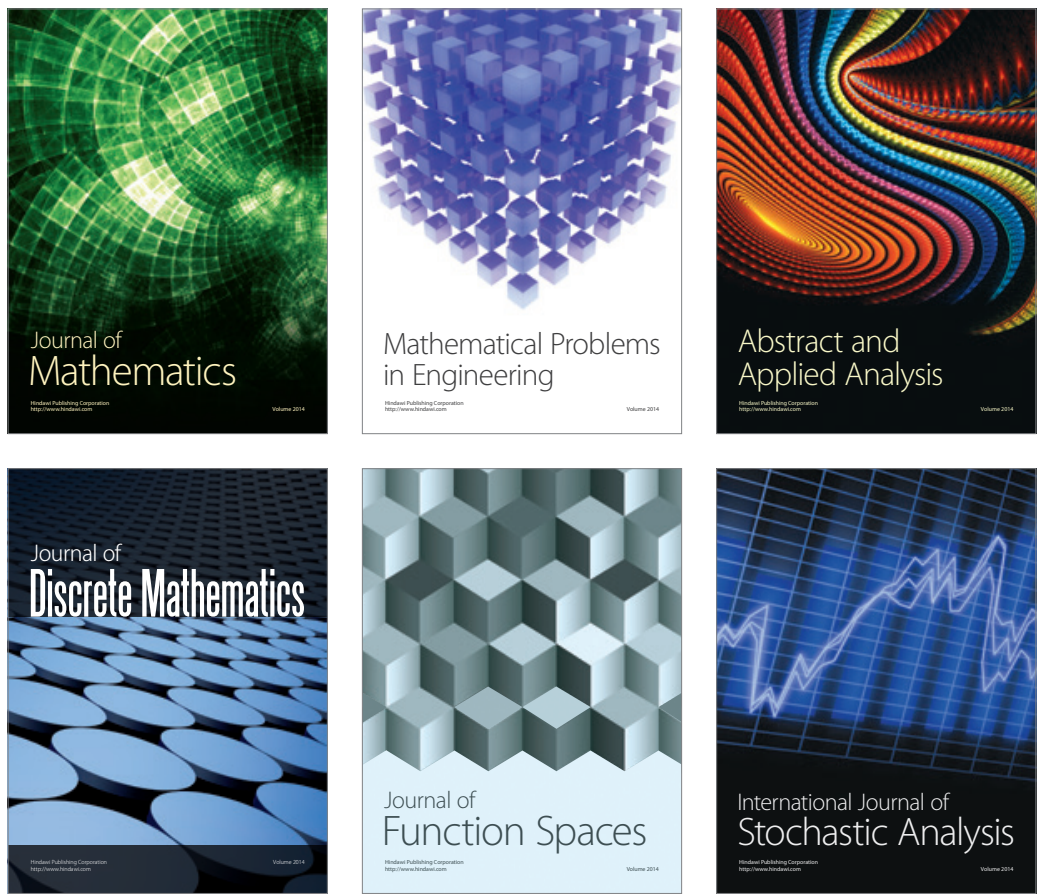

Journal of

Function Spaces

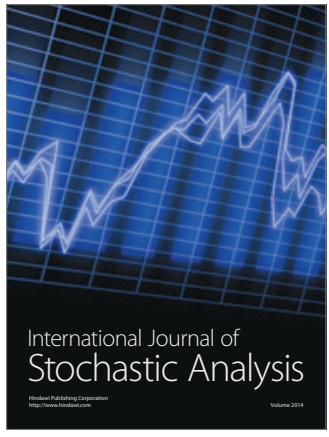

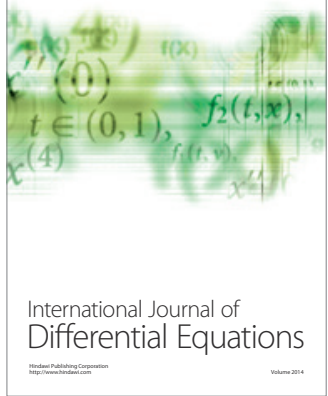
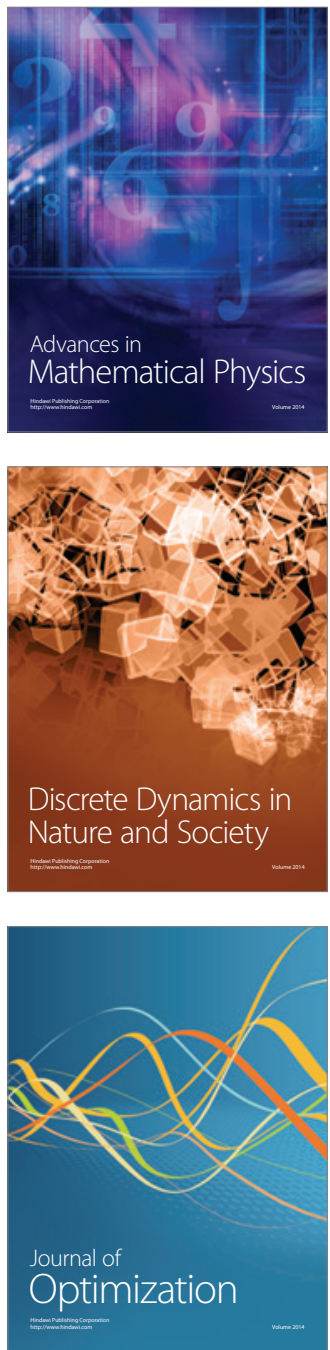